\title{
REFLEXÕES DA CONCEPÇÃO E CONSTITUIÇÃO DA REDE DE EDUCAÇÃO AMBIENTAL DA ALTA PAULISTA
}

Angélica Góis Morales ${ }^{1}$

Larissa Albuquerque de Castro ${ }^{2}$

Lais Regagnan Dias ${ }^{3}$

RESUMO: A educação ambiental, com base nos movimentos ambientalistas, busca por meio de um saber socioambiental pensar, refletir e agir na sociedade de maneira a valorizar a relação ser humano e natureza numa relação intrinsecamente interdependente. No Brasil, na busca do fortalecimento da educação ambiental foi criada algumas redes, como a Rede Brasileira de Educação Ambiental (REBEA) em meados da década de 1990, expandindo-se principalmente no inicio do século XXI, como Rede Paulista de Educação Ambiental (REPEA), a Rede de Educação Ambiental do Paraná (REA-PR) entre outras, no intuito de integrar, articular e difundir as ações em educação ambiental. As redes exercem um importante papel de expansão e aprofundamento de ações, seja em uma comunidade local ou regional. A fim de promover a ampliação e o desenvolvimento da Educação Ambiental no munícipio de Tupã e na região da Alta Paulista, foi constituída a Rede de Educação Ambiental da Alta Paulista (REAP), que visa à inter-relação dos profissionais que trabalham com educação ambiental nessa região, para o fortalecimento e expansão de

\footnotetext{
${ }^{1}$ Licenciada em Ciências Biológicas (UNESP, mestre em Educação Ambiental (FURG-RS) e doutora em Meio Ambiente e Desenvolvimento (UFPR,PR). Atua na UNESP - Univ. Estadual Paulista, Câmpus de Tupã, como docente do curso de Administração e coordenadora do projeto de extensão "Rede de Educação Ambiental da Alta Paulista", com financiamento da PROEX.

${ }^{2}$ Discente no curso de Administração de Empresas e Agronegócios, Univ. Estadual Paulista - UNESP, larialbuquerque_@hotmail.com.

${ }^{3}$ Discente no curso de Administração de Empresas e Agronegócios, Univ. Estadual Paulista - UNESP, lais_dias147@hotmail.com.
} 
formas de integração e articulação entre instituições, órgãos públicos e educadores ambientais, comunicando, discutindo e realizando projetos e ações que compreende a temática da Educação Ambiental. Nesse processo de criação e estudo da concepção de redes, esse artigo tem o propósito de tecer reflexões acerca da constituição da REAP mediante o estudo sobre e na tentativa da promoção de parcerias e acordos numa construção coletiva, com ênfase da educação ambiental.

Palavras-chave: Redes. Educação ambiental. REAP.

\section{INTRODUÇÃO}

A educação ambiental cada vez mais é um tema emergente e, no cenário brasileiro, desde a publicação da Política Nacional de Educação Ambiental (Lei n.9795/1999), observa-se que ela vem sendo impulsionada ainda mais, o que implica adentrar em diversos setores e segmentos da sociedade. Nessa caminhada, a Educação Ambiental assume uma função política e transformadora, trazendo como cerne, a busca da participação e da co-responsabilidade dos cidadãos para tomarem decisões frente ao tema socioambiental. E, é diante desse contexto, que outras formas de organização que não seja piramidal e centralizada vem ganhando espaço na sociedade atual, como a organização em redes, que busca uma compreensão sistêmica do mundo e criando conexões ocultas (MORALES et al., 2010; CAPRA, 2002).

As redes são sistemas organizacionais que reúnem indivíduos e instituições de forma democrática e participativa em torno de objetivos e de temáticas comuns. São flexíveis e se estabelecem por relações horizontais, interconexas que ocorrem através do trabalho colaborativo e participativo (MARTINHO, 2003). Sustentam-se pela vontade e afinidade de seus integrantes caracterizando-se como um significativo recurso organizacional, tanto para as relações pessoais quanto para a estruturação social.

As redes também possuem as características de multiliderança e descentralização no qual Martinho (2003, p.47) revela que tais características quando exercitadas produzem a dinâmica multifacetada, soluções originais e ideias inovadoras próprias que a organização em rede supõe. As redes, ainda segundo Amaral (2004), 
promovem a ligação entre as pessoas, bem como a interconexão entre os elos e suas relações, assumindo uma nova forma de organização.

Segundo Martinho (2003) a criação de redes teve seu auge na década de 1990, onde as redes de educação ambiental foram pioneiras nesse processo. Após a Conferência das Nações Unidas sobre o desenvolvimento Sustentável, conhecida como RIO 92, foram criadas a Rede Brasileira de Educação Ambiental (REBEA) e a Rede Paulista de Educação Ambiental (REPEA) e, por ser as redes mais antigas do país, são vistas como exemplos de amadurecimento e concretização do potencial dessa forma de organização.

A REBEA, criada em 1992 e por meio da grande mobilização e discussão da educação ambiental durante a Rio-92, surge com o desejo político e idealista de "(...) manter viva a articulação nacional dos educadores ambientais brasileiros" (REBEA, 2012). Nesse processo inicial, adotaram como pressupostos a "Carta da Terra" e o "Tratado de Educação Ambiental para Sociedades Sustentáveis e Responsabilidade Global" e como padrão organizacional a estrutura horizontal em rede, a fim de articular pessoas, profissionais da área, mas de forma que pudessem manter os contatos e as articulações, fortalecendo o campo da educação ambiental nacionalmente. Desde então, com a experiência desse processo, bem como sua expansão e fortalecimento de suas articulações no país inteiro, houve desdobramentos de outras Redes, como a Rede Pantanal de Educação Ambiental (rede Aguapé), Rede de Educação Ambiental do Paraná (REA-PR), entre outras.

A educação ambiental, com base nos movimentos da rede, realizados por meio de encontros, oficinas, e divulgação da informação, busca por meio de um saber socioambiental pensar, refletir e agir na sociedade de maneira a valorizar a relação ser humano e natureza numa relação intrinsecamente interdependente. Frente ao exposto, com o intuito de obter-se um ambiente mais coletivo, auto-organizado, isonômico e horizontal que promove inter-relações de profissionais que trabalham com Educação Ambiental na região da Alta Paulista, na tentativa de integrar projetos e ações sobre a temática ambiental, dá-se início a criação da Rede de Educação Ambiental da Alta Paulista (REAP), por meio de um projeto de extensão realizado na Universidade Estadual Paulista "Júlio de Mesquita Filho", Câmpus de Tupã, SP. 
Portanto, esse artigo pretende retratar a organização inicial da REAP, apontando as etapas necessárias para a reunião de pessoas que atuam diretamente com esse tema na região da Alta Paulista, a fim de somar esforços para o desenvolvimento de programas e projetos de EA e a cooperar com informações entre os membros participantes dessa rede, com a REBEA e outras redes estaduais, fortalecendo os elos da região da Alta Paulista.

\section{MATERIAL E MÉTODO}

A metodologia adotada nesse projeto é totalmente participativa, levando-se em consideração o encaminhamento da pesquisa-ação, que segundo Thiollent (2008), busca a compreensão entre pesquisadores e membros da situação investigada e, da analise qualitativa, já que em redes pressupõe trabalhos coletivos e colaborativos. Os sujeitão chamados a se envolver e participar da REAP são pessoas que atuam na área de educação ambiental do Município de Tupã e da região da Alta Paulista.

A região da Alta Paulista é uma antiga região ferroviária do estado de São Paulo colonizada em maior escala a partir da primeira metade do Século XX, segundo Fabri e Tavares (2006) está compreendida pelos territórios dos seguintes municípios: Adamantina, Arco-Íris, Bastos, Dracena, Flora Rica, Flórida Paulista, Herculândia, lacri, Inúbia Paulista, Irapuru, Junqueirópolis, Lucélia, Mariápolis, Monte Castelo, Nova Guataporanga, Oriente, Osvaldo Cruz, Ouro Verde, Pacaembu, Panorama, Parapuã, Paulicéia, Pompéia, Pracinha, Queiroz, Quintana, Rinópolis, Sagres, Salmourão, Santa Mercedes, São João do Pau D'Alho, Tupã e Tupi Paulista.

Inteirando assim 33 municípios e uma área de $9.976 \mathrm{Km} 2$ e ocupam um total de 997.600 ha. Sua população total no ano de 2000 era de 392.098 habitantes, sendo $86,11 \%$ na área urbana e $13,89 \%$ na área rural. É composto basicamente por pequenos municípios, pois $84,85 \%$ têm menos de 20.000 habitantes. A região contém as bacias hidrográficas dos rios Aguapeí e Peixe, que são afluentes do rio Paraná. (FABRI;TAVARES,2006) 
A Alta Paulista possui ampla malha viária, ressaltando-se a rodovia Comandante João Ribeiro de Barros - SP 294, a rodovia SP 245 e a rodovia SP 583, com várias vicinais que permitem o escoamento da produção rural aos grandes centros, como as capitais dos Estados de São Paulo, Paraná e Mato Grosso do Sul e ao norte do pais, além de acesso a hidrovia do rio Paraná. A seguir encontra-se o mapa da localização dessa região.

Para essa interconexão de objetivos comuns, foi realizado num primeiro momento, um trabalho exploratório por meio de pesquisa bibliográfica inicial, para o conhecimento da atuação em rede e da literatura de educação ambiental. Posteriormente, foi efetuado um mapeamento do público que atua em educação ambiental na região da Alta Paulista, envolvendo os municípios: Bastos, Flora Rica, Flórida Paulista, Garça, lacri, Inúbia Paulista, Irapuru, Junqueirópolis, Lucélia, Marília, Mariápolis, Monte Castelo, Nova Guataporanga, Osvaldo Cruz, Ouro Verde, Pacaembú, Parapuã, Paulicélia, Pompéia, Pracinha, Rinópolis, Sagres, Salmourão, Santa Mercedes, São João do Pau D’Alho, Tupã e Tupi Paulista.

E, em cada munícipio, buscaram-se por meio de pesquisas nos sites de prefeituras, pesquisa de campo e contato telefônico, os contatos de Secretarias Municipais de Meio Ambiente, de Educação, Instituições escolares e professores que atuam com educação ambiental, entre outros. A partir desse levantamento inicial, por meio dos contatos obtidos, foi encaminhado o convite para um encontro presencial a fim de apresentar o significado de uma rede, saber do interesse de todos sobre a articulação e conexões que serão estabelecidas por meio da REAP e dar início aos princípios da REAP, bem como a criação do logotipo. Paralelamente, ao convite e ao dia da reunião presencial foi elaborado pelos alunos participantes do projeto, o blog, como meio de comunicação inicial e o termo de adesão dos membros da REAP .

Diante de tais encaminhamentos, e com a reunião presencial em agosto de 2012 , foi dado inicio à organização da REAP que será mais bem apresentada e discutida a seguir. 


\section{RESULTADOS: REFLEXÕES E DISCUSSÕES}

A REAP, assim como a Rede Capixaba de Educacão Ambiental (RECEA) foi planejada para ser um movimento entre educadores preocupados com a EA mantendo em foco o principio da diversidade e do respeito às diferenças para não expressar uma posição unitária (TRISTÃO, 2008).

Dessa maneira a REAP surge por meio de um projeto de extensão com a intenção de organizar a Rede de Educação Ambiental da região da Alta Paulista para melhor articulação entre indivíduos e instituições que atuam nessa área a fim de somar esforços para a construção de elos representativos de todos os segmentos da sociedade, criando sinergia e diálogo de saberes entre os atores envolvidos em ações, programas e projetos de Educação Ambiental e contribuindo na promoção de parcerias e acordos na construção coletiva de práticas e conhecimentos socioambientais locais e regionais.

Para tanto, foi realizado um mapeamento do público que atua na área na região da Alta Paulista, chegando num total de 45 contatos de e-mails e telefones de instituições públicas e privadas que possuem trabalhos, projetos e atividades em educação ambiental. Tal mapeamento só foi possível pela combinação de pesquisas em sites, por contatos telefônicos e, principalmente pela visita em algumas cidades da região. Nessa coleta de dados, observou-se que os sites de órgãos públicos, principalmente, encontram-se dados desatualizados dificultando as informações de pessoas e instituições que atuam em educação ambiental, mas, mesmo assim, obteve-se um levantamento inicial que contribuiu no estabelecimento dos primeiros contatos com essas pessoas e instituições.

E, assim, foi realizada a primeira reunião presencial da REAP no dia 21 de agosto de 2012 com a participação de 22 pessoas das cidades circunvizinhas mais 7 pessoas participantes do projeto de extensão que são alunos e docentes da Unesp, totalizando 29 pessoas. 


\section{Periádica Eletrânica

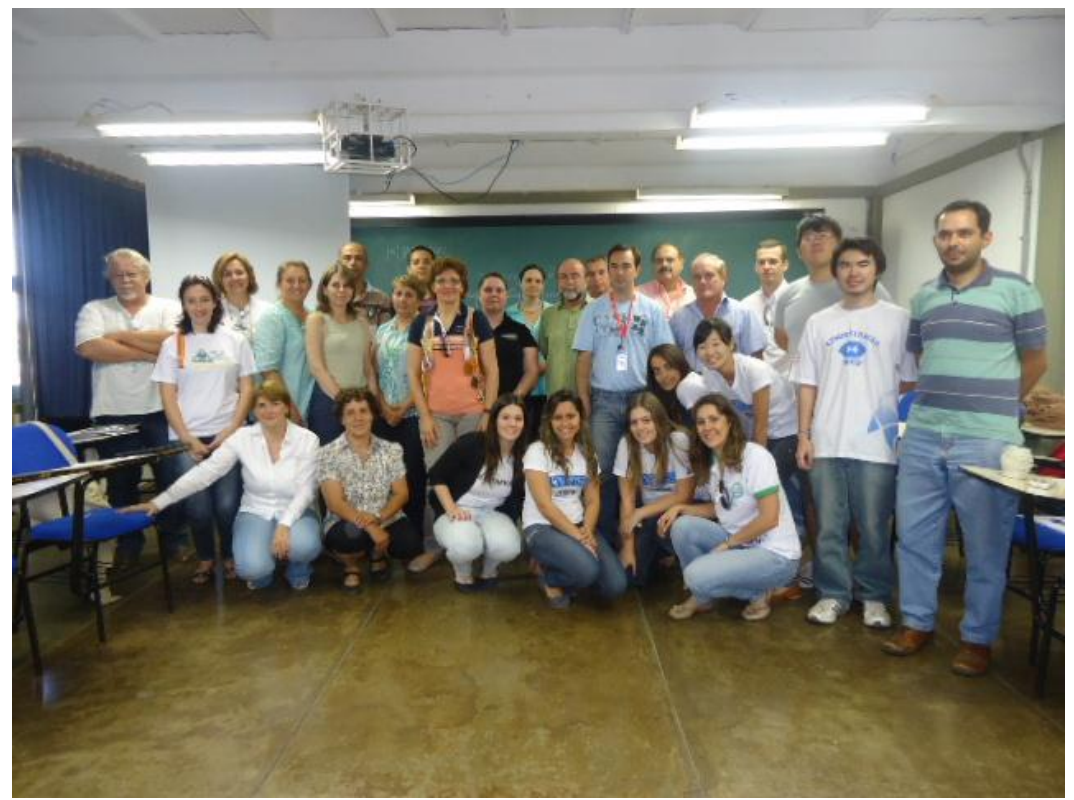

Figura 1 - Participantes da primeira reunião presencial da REAP Fonte: Os autores.

$\mathrm{Na}$ reunião foram expostas as intenções da REAP, como a justificativa e o objetivo de buscar a criação de uma rede em educação ambiental para essa região e juntamente com os participantes foi pensado junto o logotipo, apresentado o blog inicial que foi elaborado para a REAP, e também apresentado o termo de adesão para aqueles que realmente tivessem interesse em participar como membros da REAP.

Um ponto favorável da reunião foi o cadastramento e aceitação do termo de adesão de pessoas interessadas em integrar à REAP que atuam em educação ambiental nos munícipios de Marília, Bastos, Pompéia, Pacaembu, Garça, Adamantina, Tupi Paulista, Junqueirópolis Tupã. Tal participação superou as expectativas para um primeiro encontro, pois foi observado que os interesses das pessoas que participaram do evento vinham ao encontro dos objetivos da REAP.

De acordo com o termo de adesão à REAP, nota-se, conforme o quadro 1, que foram cadastrados cerca de 18 pessoas como membros participantes da REAP estão diretamente ligados, principalmente aos órgãos públicos, como Secretarias de educação e meio ambiente nas Prefeituras municipais da região e Associações, e também faculdades e universidade e ONGs. 


\begin{tabular}{|c|c|c|c|}
\hline $\begin{array}{l}\text { Nome da instituição } \\
\text { que atua/Cidade }\end{array}$ & $\begin{array}{c}\text { Área de atuação } \\
\text { em Educação } \\
\text { Ambiental }\end{array}$ & $\begin{array}{c}\text { Projetos de } \\
\text { Educação Ambiental } \\
\text { desenvolvidos }\end{array}$ & $\begin{array}{c}\text { Expectativa em } \\
\text { participar da REAP }\end{array}$ \\
\hline $\begin{array}{c}\text { Secretaria Municipal de } \\
\text { Educação } \\
\text { Tupã }\end{array}$ & $\begin{array}{l}\text { Gestora } \\
\text { Ambiental }\end{array}$ & $\begin{array}{l}\text { Desenvolvimento de } \\
\text { um programa } \\
\text { ambiental feito com } \\
\text { alunos dos } 4^{\circ} \text { anos do } \\
\text { fundamental }\end{array}$ & $\begin{array}{l}\text { Desenvolver ações } \\
\text { em parceria com a } \\
\text { Secretaria Municipal } \\
\text { de Educação do } \\
\text { município de Tupã. }\end{array}$ \\
\hline $\begin{array}{c}\text { Associação } \\
\text { Ambientalista de } \\
\text { Marília }\end{array}$ & $\begin{array}{l}\text { Câmara técnica } \\
\text { de E.A. do } \\
\text { CBHAP }\end{array}$ & $\begin{array}{c}\text { Trabalho da Ong } \\
\text { Origem no município } \\
\text { de Marília }\end{array}$ & $\begin{array}{c}\text { Buscar novos } \\
\text { métodos de trabalho } \\
\text { na educação } \\
\text { ambiental, e novas } \\
\text { parcerias. }\end{array}$ \\
\hline $\begin{array}{c}\text { Maquinas Agrícolas } \\
\text { Jacto S/A } \\
\text { Pompéia }\end{array}$ & $\begin{array}{c}\text { Gestão da } \\
\text { qualidade e meio } \\
\text { ambiente }\end{array}$ & $\begin{array}{l}\text { Gerenciamento de } \\
\text { resíduos (coleta } \\
\text { seletiva) } \\
\text { Analise de efluentes } \\
\text { industriais } \\
\text { Analise de emissão } \\
\text { atmosférica }\end{array}$ & $\begin{array}{c}\text { Multiplicar } \\
\text { informações } \\
\text { relacionadas à área } \\
\text { ambiental. }\end{array}$ \\
\hline $\begin{array}{l}\text { Prefeitura Municipal de } \\
\text { Pacaembu }\end{array}$ & $\begin{array}{l}\text { Promover ações } \\
\text { na rede de ensino } \\
\text { municipal e na } \\
\text { comunidade. }\end{array}$ & $\begin{array}{l}\text { Lei municipal para a } \\
\text { forma transversal de } \\
\text { E.A. no ensino } \\
\text { fundamental e no } \\
\text { município de } \\
\text { Pacaembu. }\end{array}$ & $\begin{array}{l}\text { Aprender mais sobre } \\
\text { educação ambiental }\end{array}$ \\
\hline $\begin{array}{l}\text { Cati-C. A de Tupã. } \\
\text { Coordenadoria de } \\
\text { Assistência Técnica } \\
\text { Integral de Tupã }\end{array}$ & $\begin{array}{c}\text { Programa } \\
\text { Estadual de } \\
\text { Microbacias } \\
\text { Hidrográficas } \\
\text { (PEMBH-1) } \\
\end{array}$ & $\begin{array}{l}\text { Ações em educação } \\
\text { ambiental no PEMBH }\end{array}$ & $\begin{array}{c}\text { Oportunidade de troca } \\
\text { de informações e } \\
\text { experiências }\end{array}$ \\
\hline $\begin{array}{l}\text { Prefeitura Municipal de } \\
\text { Garça }\end{array}$ & $\begin{array}{l}\text { Coordenadora do } \\
\text { programa } \\
\text { municipal de } \\
\text { educação } \\
\text { ambiental }\end{array}$ & $\begin{array}{l}\text { Campanhas como: } \\
\text { semana da agua, dia } \\
\text { do meio ambiente, } \\
\text { entre outros. }\end{array}$ & Trocar informações \\
\hline $\begin{array}{l}\text { Secretaria Verde e } \\
\text { Meio Ambiente do } \\
\text { município de Garça }\end{array}$ & $\begin{array}{l}\text { CEA - centro de } \\
\text { educação } \\
\text { ambiental }\end{array}$ & $\begin{array}{c}\text { Programa de } \\
\text { educação ambiental } \\
\text { desenvolvidos no } \\
\text { CEA }\end{array}$ & $\begin{array}{c}\text { Troca de } \\
\text { experiências, } \\
\text { informações sobre } \\
\text { educação ambiental. }\end{array}$ \\
\hline $\begin{array}{l}\text { Emei Dr José Francisco } \\
\text { Ferreira/ Pacaembú }\end{array}$ & $\begin{array}{l}\text { Vice-presidente } \\
\text { da CONSEMMA }\end{array}$ & $\begin{array}{c}\text { Projeto coleta de lixo } \\
\text { seletivo } \\
\text { Projeto agua } \\
\text { Projeto adote uma } \\
\text { praça } \\
\text { Projeto combate a } \\
\text { poluição }\end{array}$ & $\begin{array}{l}\text { Ajudar e aprender } \\
\text { com o grupo }\end{array}$ \\
\hline
\end{tabular}




\begin{tabular}{|c|c|c|c|}
\hline $\begin{array}{c}\text { FAl } \\
\text { Faculdades Integradas } \\
\text { Adamantinenses }\end{array}$ & $\begin{array}{l}\text { Docente na } \\
\text { faculdade FAI }\end{array}$ & $\begin{array}{c}\text { Educação ambiental } \\
\text { critica e participativa } \\
\text { na bacia hidrográfica } \\
\text { das escolas } \\
\text { jurisdicionadas a D.E. } \\
\text { de Adamandina. } \\
\text { Produção de cartilhas } \\
\text { de E.A. }\end{array}$ & $\begin{array}{c}\text { Articulação na } \\
\text { temática de educação } \\
\text { ambiental. }\end{array}$ \\
\hline $\begin{array}{l}\text { Secretaria do meio } \\
\text { ambiente do município } \\
\text { de Marilia - centro de } \\
\text { educação ambiental }\end{array}$ & $\begin{array}{l}\text { Professora de } \\
\text { educação } \\
\text { ambiental }\end{array}$ & $\begin{array}{l}\text { Computador usado } \\
\text { não é lixo! Recicle } \\
\text { O Pulo do Gato } \\
\text { Horta Sustentavel } \\
\text { Coleta de óleo de } \\
\text { cozinha usado } \\
\text { Arborização Urbana }\end{array}$ & $\begin{array}{c}\text { Troca de experiências } \\
\text { e enriquecimento do } \\
\text { trabalho desenvolvido } \\
\text { no CEA-Marília }\end{array}$ \\
\hline $\begin{array}{l}\text { Prefeitura Municipal de } \\
\text { Junqueirópolis }\end{array}$ & $\begin{array}{l}\text { Secretaria da } \\
\text { educação do } \\
\text { município de } \\
\text { Junqueirópolis }\end{array}$ & $\begin{array}{c}\text { Cartilhas sobre meio } \\
\text { ambiente }\end{array}$ & $\begin{array}{l}\text { Busca de novas } \\
\text { experiências }\end{array}$ \\
\hline $\begin{array}{l}\text { Prefeitura Municipal de } \\
\text { Tupi Paulista }\end{array}$ & $\begin{array}{l}\text { Coordenadora de } \\
\text { meio ambiente }\end{array}$ & $\begin{array}{l}\text { Coleta seletiva, água, } \\
\text { micro bacias. }\end{array}$ & Troca de experiências \\
\hline $\begin{array}{c}\text { Faculdades } \\
\text { Adamantinenses } \\
\text { Integradas } \\
\text { Adamantina }\end{array}$ & Professora & $\begin{array}{c}\text { Educação ambiental } \\
\text { formal }\end{array}$ & $\begin{array}{l}\text { Compartilhamento de } \\
\text { experiências }\end{array}$ \\
\hline $\begin{array}{l}\text { Sabesp } \\
\text { Tupã }\end{array}$ & $\begin{array}{c}\text { Promove } \\
\text { palestras sobre o } \\
\text { uso correto da } \\
\text { água }\end{array}$ & Reflorestamento & $\begin{array}{l}\text { Adquirir novos } \\
\text { conhecimentos }\end{array}$ \\
\hline $\begin{array}{c}\text { APTA, Polo Regional } \\
\text { Alta Paulista - Agência } \\
\text { Paulista de Tecnologia } \\
\text { em Agronegócio. }\end{array}$ & $\begin{array}{l}\text { Execução de } \\
\text { ações em } \\
\text { educação } \\
\text { ambiental }\end{array}$ & $\begin{array}{l}\text { Atividades do dia } \\
\text { mundial da agua } \\
\text { Palestras sobre o } \\
\text { plantio de mudas }\end{array}$ & $\begin{array}{l}\text { Realizar projetos de } \\
\text { educação ambiental }\end{array}$ \\
\hline $\begin{array}{c}\text { Prefeitura Municipal de } \\
\text { Bastos }\end{array}$ & $\begin{array}{c}\text { No município de } \\
\text { Bastos, } \\
\text { Engenheiro } \\
\text { Ambiental. }\end{array}$ & $\begin{array}{c}\text { Preservação de } \\
\text { nascentes } \\
\text { Áreas de preservação } \\
\text { permanente } \\
\text { Coletas de } \\
\text { embalagens de } \\
\text { agrotóxicos }\end{array}$ & $\begin{array}{c}\text { Poder colaborar com } \\
\text { a rede e trocar } \\
\text { experiências }\end{array}$ \\
\hline $\begin{array}{c}\text { APTA Marília - Agência } \\
\text { Paulista de Tecnologia } \\
\text { em Agronegócio }\end{array}$ & $\begin{array}{l}\text { Criação de } \\
\text { projetos sobre } \\
\text { educação } \\
\text { ambiental } \\
\end{array}$ & $\begin{array}{c}\text { Uso racional de agua } \\
\text { na agricultura }\end{array}$ & $\begin{array}{c}\text { Contribuir com } \\
\text { informações ligadas a } \\
\text { educação ambiental }\end{array}$ \\
\hline $\begin{array}{c}\text { ANAP Tupã } \\
\text { Associação Amigos da } \\
\text { Natureza da Alta } \\
\text { Paulista }\end{array}$ & $\begin{array}{c}\text { Desenvolvimento } \\
\text { de projetos pela } \\
\text { Ongs. }\end{array}$ & $\begin{array}{l}\text { Jornal ecolegal } \\
\text { Fórum ambiental }\end{array}$ & $\begin{array}{c}\text { Aumentar a rede de } \\
\text { contatos e realizar } \\
\text { projetos. }\end{array}$ \\
\hline
\end{tabular}




\begin{tabular}{|c|c|c|c|}
$\begin{array}{c}\text { UNESP Tupã } \\
\text { Jniversidade Estadual }\end{array}$ & $\begin{array}{c}\text { Docente e alunos } \\
\text { do curso de } \\
\text { Administração }\end{array}$ & $\begin{array}{c}\text { Programa televisivo } \\
\text { Olhar Ambiental } \\
\text { Projetos em educação } \\
\text { e gestão ambiental }\end{array}$ & $\begin{array}{c}\text { Proporcionar para a } \\
\text { região uma forma de } \\
\text { comunicação e } \\
\text { organização que } \\
\text { integrem as ações em } \\
\text { educação ambiental. }\end{array}$ \\
\hline
\end{tabular}

Quadro 1 - Relação dos membros e elos participantes da organização inicial da REAP

Fonte: Elaborado pelos autores.

Também é possível verificar que há atividades sendo desenvolvidas em educação ambiental, umas ligadas diretamente a um programa ou projeto maio, e outras como práticas ambientais, ainda pontuais, mas que estão diretamente envolvidas com a discussão em educação ambiental. E, as expectativas estão centradas na troca de saberes no campo da educação ambiental, bem como estabelecer parcerias dentro dessa forma de organização horizontal e de muitas conexões. O mais interessante foi observar que tinham pessoas que atuam na mesma cidade e que não conheciam os outros trabalhos desenvolvidos em educação ambiental, como notado nos depoimentos de alguns durante a reunião presencial.

Após essa junção de elos movidos pelo saber ambiental foi criada uma lista de discussão online para a socialização e discussão sobre informações em educação ambiental, notícias e comunicados, obtendo um ambiente comum de comunicação entre esses elos, para possíveis formações de grupos de estudo sobre a educação ambiental. Foi elaborado também o blog ${ }^{4}$ da REAP tendo como fim a divulgação de informações de eventos, cursos e ações sobre a temática Educação Ambiental de Tupã e região que compõe a Alta Paulista, no entanto, ainda está na fase de construção coletiva.

Pode-se constatar que ao organizar os integrantes da REAP em forma de rede, observa-se que esse tipo de comunicação abre um espaço coletivo de aprendizagem, contribuindo na realização de parcerias que agregam conhecimentos socioambientais na região da Alta Paulista.

A REAP, tal como a Rede Paulista de Educação Ambiental (REPEA), possui escassez de recursos financeiros devido ao fato de dependerem exclusivamente de voluntários e de parcerias, pois suas ações não objetivam retorno financeiro. Essa

\footnotetext{
${ }^{4}$ O Blog "reap.unesptupa.blogspot.com.br está criado, mas sua construção está sendo de forma coletiva de acordo com as discussões e apreciações do grupo por meio da lista de discussão do gmail.
} 
escassez de recursos embora prejudique 0 desenvolvimento de algumas ações ambientais não é uma barreira que impeça as redes de cumprir seus objetivos (GUERRA, et al., 2008).

Nessa configuração de redes que propõe estabelecer conexões, também é importante chamar atenção para alguns encaminhamentos que são necessários para exercitar o diálogo entre saberes de forma horizontal. São eles: capacidade de autoorganização pelo modo da inter-relação dos participantes; comunicação não-linear, no qual estende-se em todas as direções; dinâmica de conectividade; multiliderança e descentralização (CAPRA, 2002; MARTINHO, 2003).

O projeto de extensão da REAP, ainda em andamento, tenta promover a articulação de projetos e pessoas que tornam cada vez mais potencializadas as ações da temática da educação ambiental na região. A lista de discussão reap.unesptupa@gmail.com ainda encontra-se com pouca animação e participação, mas em breve será realizado um curso sobre ferramentas que contribuem na discussão online.

Tendo em vista as ações já promovidas, pretende-se posteriormente ampliar a rede de tal forma que haja compreensão e participação ativa de todos os ambientalistas ou envolvidos com o movimento ambiental.

Pretende-se ainda realizar um Fórum de Educação Ambiental para estabelecer a articulação entre os elos que atuam na área e elaborar de forma conjunta a carta de convivência, as ações e os princípios da Rede de Educação Ambiental da Alta Paulista e, após esses documentos estabelecidos de forma coletiva, espera-se a inserção da REAP na REBEA objetiva se que promova ações em todas as localidades dentro da região e fora dela, para que a existência e a ideia de propague nas comunidades.

\section{CONSIDERAÇÕES}

A partir da análise e reflexão da concepção de rede e da constituição inicial da REAP observa-se que os membros participantes buscam por meio dessa rede, a articulação e parceria entre os indivíduos e instituições interessados nesse assunto para fortalecer sua relação e melhorar o desempenho dos mesmos na região. 
Com a criação do blog, os interessados poderão se conhecer e se comunicar para facilitar divulgações de eventos, diálogo de saberes, entre outras ações.

Embora a rede esteja constituída, para que ela seja utilizada com frequência e ajude as pessoas interessadas é necessário interesse e investimento dos dois lados, tal como foi citado por Martinho (2003, p.43)

A primeira pré-condição da rede é a participação voluntária. Aqui reside, talvez, uma das razões mais simples da capacidade da rede de trabalhar sem hierarquia: pessoas (ou organizações) participam da rede quando querem e porque assim o desejam. Elas não são obrigadas a fazê-lo; decidem compartilhar do projeto coletivo da rede porque acreditam e investem nele.

É visível que a rede poderá auxiliar muito as pessoas ligadas a esse assunto porém, para que a rede possa caminhar para melhor articulação, é necessário não somente a dedicação dos moderadores ou facilitadores da REAP, mas sim de todos os membros nela presente para que haja discussões e buscas por melhorias.

A REAP objetiva futuramente aumentar sua participação nas ações ambientais da região, bem como promovê-las para ajudar na difusão do assunto de EA e contribuir na sensibilização ambiental da região.

\section{REFERÊNCIAS BIBLIOGRÁFICAS}

AMARAL, V. Redes sociais e redes naturais: a dinâmica da vida. 2004. Disponível em: http://www.rits.org.br/redes teste/rd tmes fev2004.cfm. Acesso em: 10 jun. 2012.

CAPRA, F. As conexões ocultas: ciência para uma vida sustentável. São Paulo: Cultrix, 2002.

FABRI, E. G.; TAVARES, P. E. da R. A região da Alta Paulista e suas potencialidades na produção de corantes naturais. Pesquisa e tecnologia, v.3, n.2. Jul/Dez 2006. Disponível em: $\quad<h t t p: / / w w w . a p t a r e g i o n a l . s p . g o v . b r / i n d e x . p h p / c o m p o n e n t / d o c m a n / d o c$ view/365-aregiao-da-alta-paulista-e-suas-potencialidades-na-producao-de-corantesnaturais? Itemid=284 >. Acesso em: 06 abr. 2012

MARTINHO, Cássio; REDES: uma introdução às dinâmicas da conectividade e da autoorganização. Brasília: WWF-Brasil, 2003. 
MORALES, A.G. et al. Ação Extensionista fortalecendo a Rede de Educação Ambiental do Paraná. Revista Conexão, Ponta Grossa: UEPG, v. 6, p. 40-46, 2010.

REBEA. Rede Brasileira de Educação Ambiental: quem somos? Disponível em: http://www.rebea.org.br/arquivorebea/quemsomos.htm. Acesso em: 116 out. 2012.

THIOLLENT, M. Metodologia da Pesquisa-ação. São Paulo: Cortez, 2008.

TRISTÃO, M. A Tessitura da rede capixaba de Educação Ambiental (RECEA): Um modo de pensar e agir coletivamente. Revista brasileira de Educação Ambiental, Brasília: Rede brasileira de Educação Ambiental, n. 03, p.53, 2008.

GUERRA, A. F. S.; LIMA, A.; JUSTEN, L. M.; GARUTTI, M. L. F. As redes no espelho: conceitos e praticas da cultura de redes de educação ambiental. Revista brasileira de Educação Ambiental, Brasília: Rede brasileira de Educação Ambiental, n. 03, p.83, 2008. 